\title{
Balões entre fogueiras e bondes: itinerário de um grande poeta menor
}

\author{
Roberta Maria Ferreira Alves*
}

\begin{abstract}
RESUMO
$\mathrm{O}$ presente texto pretende analisar como as viagens ultrapassam tempo e espaço, tradição e modernidade, no fazer poético de Manuel Bandeira, retomando, de forma singela, as representações do imaginário social, as relações imagéticas que atuam na memória afetivo social da cultura na qual o poeta está inserido. Pretende-se, ainda, desvelar que a obra de Bandeira assegura o contato com um cotidiano e com uma memória coletiva, ambos se posicionando como depositários das reminiscências ao longo das vivências. Propõe-se evidenciar, com a ajuda das reflexões de Bronislaw Baczko, que, na obra de Bandeira, tais elementos, incorporam visões de mundo e modelam condutas e estilos de vida, ao mesmo tempo registrando os movimentos de preservação da ordem vigente e de anúncio de mudanças.

Palavras-chave: Manuel Bandeira. Viagens. Memória. Tradição e modernidade. Imaginário social.
\end{abstract}

Era uma vez um adulto que contava histórias de uma época para ele aparentemente tão distante:

Quando ontem adormeci

Na noite de São João

Havia alegria e rumor

Estrondos de bombas luzes de Bengala

(...).

Quando eu tinha seis anos

Não pude ver o fim da festa de São João

Porque adormeci.

(BANDEIRA, 2007, p.139).

Como em um conto de fadas, o poeta transporta-se para a infância e, nesse momento, espreita uma criança feliz, em uma tentativa vã de se sentir completo.

Por diversas vezes, (re)começamos este texto. Afinal, profundamente apaixonados, estabelecemos como meta fazer uma abordagem sobre um poeta que, apesar de ser considerado um dos maiores da literatura brasileira, se intitulava

* Professora da Universidade Federal dos Vales do Jequitinhonha e Mucuri - UFVJM. 
poeta menor. Ironicamente, buscando elogios, criticamente avaliando seu trabalho? $\mathrm{Na}$ verdade, por crer que a temática de sua poesia não alcançava os grandes temas filosóficos abordados por outros poetas, mas, e sim, aqueles que se desenhavam com traços do cotidiano, porém, repleta de musicalidade incomum e flutuante, Bandeira se desenhou/esboçou dessa maneira: poeta menor. Sabemos que essa denominação torna nosso trabalho profundamente árduo, profundamente singelo, profundamente comprometido, profundamente...

Pernambucano, natural do Recife, Manuel Carneiro de Souza Bandeira Filho foi lido por Machado de Assis e viveu para além de Guimarães Rosa e, em sua jornada literária, dialogou estreitamente com os poetas representantes da chamada tradição e da divulgada modernidade, o que nos permite perceber um autor entre extremos temporais e estilísticos.

Não podemos vislumbrar a poética de Bandeira como um mero ecletismo formal, o qual rotulamos como um manancial de estilos que engloba, desde tendências últimas do século XIX em suas singulares releituras, até as experienciadas formas concretas do século XX. A obra do poeta recifense não apresenta progressão linear na qual o jeito de compor tradicional foi paulatinamente descartado, e/ou trocado, por uma forma não tão tradicional assim. O que ocorre, na obra como um todo, é um diálogo entre tradição e modernidade, que se concretiza através de um trabalho singular e ímpar. Tal percepção pode ser confirmada pelas palavras do próprio poeta:

Chamo poeta $100 \%$ o poeta que sabe nadar em todas as águas: no oceano em completo perpétuo movimento do verso livre e... nos blocos congelados da forma fixa. (...) as orientações modernistas foram muitas e em alguns pontos contraditórias: a que me parecia melhor era a que procurava conciliar as duas forças em eterno conflito na vida - tradição e renovação. (SENNA, 1968, p.58).

Através de sua própria definição de poeta, Bandeira nos permite intuir como o poeta via esse trânsito. Apenas os que fossem capazes de navegar entre tradição e modernidade poderiam ser avaliados como poetas completos. Sobre isso, Drummond, em sua leitura de Bandeira, afirmou:

Para mim, isso revela a variedade de interesses literários de Bandeira. Ao mesmo tempo, demonstra que ele foi um mestre em todas as formas de poesia. Bandeira mostrou, na prática, todas as possibilidades poéticas do seu tempo. Assim, através de sua poesia, podemos, inclusive, entender melhor o percurso da própria poesia brasileira. (DRUMMOND apud SILVA, 1989, p. 6). 
Conseguir construir uma poética com traços tão incomuns quase elimina o sentido de distinguir, de deliberar, na obra de Bandeira, o que é convencional e o que é inventado, uma poesia com uma forma arrebatadora e necessária, capaz de amalgamar com naturalidade técnicas diversas, uma forma de liberdade tão acolhida pelo próprio modernismo, liberdade que lhe permitia dialogar com a tradição parnasiana e simbolista de forma criativa e singular, bem ao estilo da modernidade.

Um ser em circulação constante, um viajante que em seu trânsito pela tradição e pela modernidade também soube organizar sua bagagem com as fontes mais heterogêneas que abrangeram desde traduções de grandes poetas e escritores, suas próprias experiências, notícias de jornal, bulas de remédios, anamneses, sintomas de doenças, propagandas, pregões populares, homenagem aos amigos, ditados populares até o "disse-me-disse" entre amigos, afinal "a poesia está em tudo" - tanto nos amores como nos chinelos, tanto nas coisas lógicas como nas disparatadas. (BANDEIRA, 1984, p.19).

Em momento de profunda ousadia, daremos ao autor de "Balada das três mulheres do sabonete Araxá" (BANDEIRA, 1998) um título novo: viajante, que obteve sua poética especializada nas linhas desenhadas pelas estéticas parnasianas e simbolistas, nas quais a poesia era vista como algo obtido através do exclusivo, do elevado e do raro. Bandeira consegue demonstrar que a poesia também pode brotar do cotidiano, transformando-se, assim, em alguém que, além de aderir às questões abraçadas pelo modernismo, ajudou de forma exemplar a rascunhar e construir a linguagem poética moderna.

Um viageiro temporal, que nasceu ao final da Monarquia brasileira e que teve o privilégio de vislumbrar diversas fases da República de seu país, em diálogo constante com o viajante geográfico que, em busca de sobrevivência e de climas mais amenos e objetivando a cura para uma tuberculose adquirida aos 18 anos, Bandeira transitou por diversas cidades brasileiras e estrangeiras, em viagens que facultaram a nosso poeta uma percepção incomum, tanto das questões ideológicas (tempo), quanto das culturais (espaço) de seu tempo.

E, como se não bastassem tantos adjetivos para nosso viajante, seja ele temporal, seja geográfico, Bandeira se estabelece como viajante poético, que faz a travessia da espontaneidade, decorrente de um constante estado de "alumbramento", à técnica, sem perder o momento, o tato para perceber o que há de poesia no instante e, de forma singela, reproduzi-lo através de palavras.

Simples e emotivo, é capaz de externar as emoções através de uma técnica exemplar e muita concentração naquilo que faz e, por isso, é capaz de permitir que 
essa citada simplicidade se desenhe com uma sofisticação que alcança o sublime em diálogo constante com outras artes, especialmente, com a música.

Depois do que foi (d)escrito, de qual viajante falaremos? De quais terras percorridas? De qual tempo vivido? Tomemos como ponto de partida a infância visitada por um homem adulto que, devido a uma necessidade subjetiva de reconquistar tempo e espaço passados, apresenta-nos, com suas palavras, tentativas de recuperação de histórias vividas. $\mathrm{O}$ que em seu momento presente se encontra perdido. Esse viajante busca na infância, espaço da saúde, da ingenuidade, da espontaneidade, da simplicidade e da plenitude, ornados por uma aura mágica e sagrada de um paraíso perdido, sua (de)cantada Pasárgada.

Em seus textos sobre a infância, Bandeira nos permite perceber o aparecimento de algo muito maior e mais forte do que as lembranças de um adulto; algo de mítico e real que se articula desenhando um passado vivido e imaginário que, em sua reatualização, é capaz de fazer com que as emoções infantis operem como matrizes da sensibilidade poética de seu autor.

Assim, nossa viagem ao lado desse viajante híbrido será feita, a partir de agora, lado a lado com as palavras do poeta. Nelas, tentaremos tecer vínculos de um ir e vir temporal, em uma tentativa de desnudar o espelhamento do imaginário de épocas que o poeta viveu, um diálogo que intentará ultrapassar o tempo da escrita e se constituirá no instante da leitura. O ponto de partida: a memória. Através de flashes que não obedecem a uma ordem linear, mas, sim, se configuram como tentativas de preenchimentos e respostas para nossas divagações, partiremos de uma biografia mnemônica que encontramos no poema "Infância", parte do livro Belo belo (1948):

\author{
Corrida de ciclistas \\ Só me recordo de um bambual debruçado no rio. \\ Três anos? \\ Foi em Petrópolis. \\ Procuro mais longe em minhas reminiscências. \\ Quem me dera lembrar da teta negra de minh'ama-de-leite... \\ Meus olhos não conseguem romper os ruços definitivos do tempo ... \\ (BANDEIRA, 2007, p. 208).
}

Um adulto que precisa reconstruir epifanicamente sua infância para se sentir partícipe de sua própria vida, embora saiba que tal infância constituída em versos faça parte do imaginário e não do vivido. Como o próprio poeta afirma em Itinerário de pasárgada (1984): 
Procurarei fixá-las (reminiscências) no poema "Infância"; uma corrida de ciclistas, um bambual debruçado no rio (...) o que há de especial nessas reminiscências (...) é que, não obstantes serem tão vagas, encerram para mim um conteúdo inesgotável de emoção. A certa altura da vida vim a identificar essa emoção particular com outra, a de natureza artística. (BANDEIRA, 1984, p. 17).

O poema nos brinda com um diálogo constante entre o grande poeta e o passado representado pelo menino que construiu suas memórias como um viajante, a memória delineada através dos acontecimentos, personagens e locais. Em uma viagem que se estabelece em locais específicos (Petrópolis, Recife, São Paulo, Santos, Petrópolis, Rio de Janeiro, Recife, Rio de Janeiro), em tempos desconectados de uma linearidade padrão, o adulto percebe e se diz disposto a analisar suas reminiscências:

Verifiquei ainda que o conteúdo emocional daquelas reminiscências da primeira meninice era o mesmo de certos raros momentos em minha vida de adulto: num e noutro caso alguma coisa resiste à análise da inteligência e da memória consciente, e que me enche de sobressalto ou me força a uma atitude de apaixonada escuta. (BANDEIRA, 1984, p.17).

A criança é a chave de compreensão para o mundo poético do adulto. Notamos que todos os momentos são reais e integram a unidade do poeta. O adulto coloca o menino na função basilar de sustentação do homem e da poesia. É esse menino o local de onde brota o sentimento que, de alguma forma, é sempre ressignificado nas palavras do adulto poeta, como podemos perceber nos versos finais do poema "Infância":

Com dez anos vim para o Rio.

Conhecia a vida em suas verdades essenciais.

Estava maduro para o sofrimento.

E para a poesia!

(BANDEIRA, 2007, p.208)

A articulação da memória empregada no poema nos permite dialogar com a concepção de lembrança nas palavras de Hawbuachs:

a lembrança é em larga medida uma reconstrução do passado com a ajuda de dados emprestados do presente, e além disso, preparada por outras reconstruções feitas em épocas anteriores e de onde a imagem de outrora manifestou-se já bem alterada. (HALBWACHS, 2004, p. 75-6). 
Em alguns momentos de extrema suavidade, as imagens do adulto e da criança ora se mantêm distintas, ora se fundem através de um símbolo, de uma representação. Em "Profundamente", poema que constitui o livro Libertinagem (1930), também o menino e o adulto, o sonho e a realidade, um túnel e um balão se aproximam e se distanciam:

\author{
Quando ontem adormeci \\ Na Noite de São João \\ Havia alegria e rumor \\ Estrondos de bombas luzes de Bengala \\ Vozes, cantigas e risos \\ Ao pé de fogueiras acesas. \\ (BANDEIRA, 2007, p. 139-140).
}

Um ontem que se torna mais longínquo do que o dia anterior e, ao mesmo tempo, se torna mais próximo que o dia presente, que se vive, pois ao lembrá-lo, latente se mantém e muito além das reminiscências. Tudo isso revitalizado pela alegria que, no presente, se revive ao lembrar-se de amigos, família e infância, local e tempo nos quais a felicidade se achava presente com a simplicidade de vida pulsante e boa.

Em outras palavras, a memória é sempre vivida, física ou afetivamente. No instante em que o grupo desaparece, a única forma de salvar as lembranças que, para os grupos existentes, são exteriores

\begin{abstract}
é fixá-las por inscrito em uma narrativa seguida uma vez que as palavras e os pensamentos morrem, mas os escritos permanecem. Se a condição necessária, para que haja memória, é que o sujeito que se lembra, indivíduo ou grupo, tenha o sentimento de que busca suas lembranças num movimento contínuo, como a história seria uma memória, uma vez que há uma solução de continuidade entre a sociedade que lê esta história, e os grupos testemunhas ou atores, outrora, dos fatos que ali são narrados? (HALBWACHS, 1990, p. 80-81).
\end{abstract}

Por meio de sua escrita cotidiana e singela, Bandeira fixa suas lembranças e revitaliza sensações e percepções. O imaginário social vem à tona e constrói uma noite de São João que sobreleva, em importância, a própria noite de São João que foi verdadeiramente vivida. Concentrada numa totalidade, a recordação do vivido é aliada a um sentimento de liberdade do que se presencia.

Os sentidos, como agentes da memória, nos permitem quase ouvir os barulhos característicos de estrondos, bombas, perceber o colorido das luzes de bengala, 
experimentqr a deliciosa sensação de perceber os fogos de artifícios que percorrem os céus em ocasiões tão especiais. Tais percepções conseguem transportar o sujeito lírico de seu presente silencioso na cidade que o mantém solitário para o passado repleto de alegrias e satisfações. É através de seu imaginário repleto de reminiscências que a voz do poeta alcança suas aspirações, esperanças e abandona os medos que o atormentam. Apesar de todas essas tentativas, podemos observar que, mesmo se apoiando em suas lembranças, esse momento se faz presente. Como o sujeito lírico afirma: ele acorda, desperta do mundo de sonhos que sua infância lhe permite vivenciar:

No meio da noite despertei

Não ouvi mais vozes nem risos

Apenas balões

Passavam errantes ...

(BANDEIRA, 2007, p.139-140).

Silêncio e efemeridade são marcas do momento presente e daquele proporcionado pelo cruzar dos balões pelo céu que o mantém, em uma suspensão espaço-temporal, entre presente e passado. Qual é então a diferença? O que nos permite perceber esses dois momentos? A modificação de sons. No passado, tais sons eram humanos: vozes, alegrias, sons de fogos de artifícios; e no presente do sujeito lírico, os sons são mecânicos, urbanos, distinguindo-se, assim, pelo fato de, além de temporal, ser geograficamente o local de onde o poeta percebe seu contexto. Onde se encontram os sons queridos? Nas reminiscências das lembranças? Um convite para que o leitor ultrapasse um túnel, silencioso, sem dança, sem canto, sem riso e distante das fogueiras acesas:

\author{
Silenciosamente \\ Apenas de vez em quando \\ O ruído de um bonde \\ Cortava o silêncio \\ Como um túnel. \\ Onde estavam os que há pouco \\ Dançavam \\ Cantavam \\ E riam \\ Ao pé das fogueiras acesas? \\ (BANDEIRA, 2007, p.139-140).
}

O imaginário do poeta não é uma cópia do real, mas, sim, uma das infinitas possibilidades de sentidos, em imagens expressivas. Por meio de sua imaginação, ele se liberta de um presente imediato e é motivado a explorar novos caminhos. 
Dessa forma, acontece, diante de sua insatisfação, a criação de algo alternativo, uma permissão tácita de adaptação a algo aceitável. Assim, símbolos são criados e, por não serem neutros, estão carregados de toda uma vida experienciada. Dormir se expande e se enclausura, se decodifica e se transmuta. Ambiguamente, uma pausa, ou um ato eterno emerge, a morte:

- Estavam todos dormindo

Estavam todos deitados

Dormindo

Profundamente.

(BANDEIRA, 2007, 139-140)

Uma voz responde ao sujeito lírico e, dessa vez, como em um estado de suspensão ele, entre a realidade que vive e a que recorda, satisfaz aos dois momentos, em uma preparação para despertar e acreditar que seu lugar é no presente, mesmo que apenas amenizado por sensações passadas:

\author{
Quando eu tinha seis anos \\ Não pude ver o fim da festa de São João \\ Porque adormeci \\ Hoje não ouço mais as vozes daquele tempo \\ Minha avó \\ Meu avô \\ Totônio Rodrigues \\ Tomásia \\ Rosa \\ Onde estão todos eles? \\ - Estão todos dormindo \\ Estão todos deitados \\ Dormindo \\ Profundamente. \\ (BANDEIRA, 2007, p.139-140).
}

Presente e passado se distanciam e se aproximam, desenhando, portanto, não só momentos estanques, mas fluidos, que se entrelaçam de tal forma que constroem um ser híbrido não só de passado e presente, mas também de memória e realidade, de tradição e modernidade.

O poeta, o qual tomamos a liberdade de chamar de híbrido, apresenta, como afirmamos, trabalhos de ressignificação da tradição e concretização da modernidade. Em sua primeira obra, Cinza das horas (1917), o título, bem funesto, atua de forma paratextual com os temas desenvolvidos na obra: contiguidade entre dor e solidão, morte e doença, predileção por ambientes noturnos, pela atmosfera mágica e pelos 
sons oriundos desses ambientes, a infância perdida que se tenta alcançar através da poesia, os contrastes vários, o forte erotismo, uma lírica amorosa, a forma peculiar de articular uma natureza portadora de um aprendizado para a cura e um intenso sentimento familiar.

O livro apresenta uma arquitetura capaz de reunir diferentes momentos que o compõem e, em um poema inicial, podemos perceber essa dupla composição, o sabor da inspiração aliado à técnica apurada. É o que se desnuda no poema "Epígrafe":

Sou bem nascido. Menino, Fui, como os demais, feliz. Depois, veio o mau destino E fez de mim o que quis.

Veio o mau gênio da vida, Rompeu em meu coração, Levou tudo de vencida, Rugia e como um furacão,

Turbou, partiu, abateu, Queimou sem razão nem dó -

Ah, que dor!

Magoado e só,

- Só - meu coração ardeu:

Ardeu em gritos dementes

$\mathrm{Na}$ sua paixão sombria...

E dessas horas ardentes

Ficou esta cinza fria

- Esta pouca cinza fria.

(BANDEIRA, 2007, p. 43).

Uma forma de expressão originada de elementos simples, e embora seja a abertura de uma obra com traços fortemente parnasianos e simbolistas, encontramos um poeta que consegue aliar a forma popular e a erudita em sua composição. Encontramos poemas com versos alexandrinos e octossílabos em constante diálogo com parlendas e trovas, a métrica simples com rimas que evitam formas raras. Um perceptível despojamento da tradição poética em detrimento da tradição popular.

Bandeira, em sua obra, chama atenção, principalmente, pela sintaxe e pelos cortes facilmente percebidos visualmente pelo leitor. Contudo, se direcionarmos a leitura para o poema seguinte, "Desencanto", notamos que, embora seja mantido 
o lirismo melancólico que remete a temas como a espera da morte, a frustração, a resignação de quem espera o fim, o sofrimento, a angústia e a tristeza, deparamonos com um metapoema que descreve o ato de fazer poesia como uma fuga, um desabafo de um ser que sofre e aguarda a morte:

\author{
Eu faço versos como quem chora \\ De desalento, de desencanto \\ Fecha meu livro se por agora \\ Não tens motivo algum de pranto, \\ Meu verso é sangue, volúpia ardente, \\ Tristeza esparsa, remorso vão \\ Dói-me nas veias amargo e quente, \\ Cai a gota do coração. \\ E nesses versos de angústia corre \\ Deixando um acre sabor na boca \\ - Eu faço versos como quem morre. \\ (BANDEIRA, 2007, p. 43-44).
}

Caso analisemos formalmente o poema anterior, perceberemos que está dividido em três quadras, e que a primeira constitui a apresentação, a segunda a descrição, e a terceira a conclusão do tema exposto. É um poema que segue uma padronização em sua constituição, composto por estrofes que são constituídas por versos eneassílabos, com esquema de rimas $\mathrm{ABAB}$. O esquema das rimas desenhado pelo poeta mantém uma regularidade clássica, tanto na primeira quanto na terceira estrofes e as duas últimas vogais estabelecem o esquema das rimas. Todo um padrão formal é articulado de forma tradicional.

Essa percepção delineada de forma bem simples poderia ser mais aprofundada, porém, o que pretendemos neste texto é que seja observada e comprovada nossa leitura de que a suposta simplicidade de Bandeira, em seu primeiro livro e nos demais, é desenhada por uma técnica incomparável que, aliada à sua denominada inspiração, colocam esse grande poeta como um dos maiores expoentes da poética brasileira.

Em sua obra seguinte, Carnaval (1919), encontramos um livro experimental no qual podemos perceber uma maneira sintetizada de o poeta trabalhar a partir de um tema e de suas variações, delineado intensamente pelo erotismo e por uma estratégia pouco comum em sua estilística, momento no qual a voz poética concede voz a um personagem: a prostituta em "Vulgívaga", que toma a voz e conduz a palavra.

Nessa obra também encontramos "Os sapos", célebre poema lido por Ronald 
de Carvalho em uma das noites da Semana de Arte Moderna de 1922, poema elevado pelo imaginário social ao patamar de "hino nacional do modernismo", comentadíssimo. No entanto, o que nos interessa, neste momento, é a percepção de que o poeta desqualifica os cacoetes parnasianos, criando uma paródia, colocandose, assim, como um aprendiz de novas formas, novas estéticas, mas que, ao mesmo tempo, assume ter utilizado o que agora descarta.

Os versos finais do poema, talvez, sejam mais uma chave para percebermos quem era esse grande "poeta menor":

Longe dessa grita,

Lá longe mais densa

A noite infinita

Veste a sombra imensa;

Lá, fugido ao mundo,

Sem glória, sem fé,

No perau profundo

E solitário, é

Que soluças tu,

Transido de frio,

Sapo-cururu

Da beira do rio...

(BANDEIRA, 2007, p. 80).

Surge um sujeito lírico que se encontra em um falso caminho. Quem sabe o caminho da danação, ou o da salvação? Um ser solitário que, através de imagens tão familiares, suaviza fraternalmente a dita solidão. $\mathrm{O}$ amigo Mário de Andrade o classificou como "o sapo-cururu da poesia brasileira", como portador de uma voz/ canto/poesia singular capaz de aproximar o leitor pela utilização de símbolos tão familiares que, ao mesmo tempo, permitiam um espelhamento, uma identificação capaz de consolar, acarinhar e dar esperanças a quem se permitisse o trânsito entre suas palavras.

O ritmo dissoluto se posiciona como transição entre os dois momentos da poesia do poeta pernambucano, já que, em suas palavras, o poeta afirma que "é dos meus livros aquele sobre o qual os que apreciam a minha poesia mais discordam". Em seu Itinerário de pasárgada, Bandeira cita as palavras de Adolfo Casais Monteiro, quando este define parnasianismo:

o parnasianismo quebrou definitivamente o seu instrumento de bronze; mas o que lhe ficou nas mãos não é um instrumento: são os pedaços com que o há de construir (...). Em Ritmo dissoluto 
muitas são as poesias sem ritmo de espécie alguma; mais do que ritmo dissoluto, portanto (...) Mas a maioria delas oscila entre a notação sucessiva de impressões desagregadas uma das outras e a repetição de certos temas cansados, em que a nota da melancolia se entrelaça com a da voluptuosidade, mas "sem poder de convicção". (BANDEIRA, 1984, p.74-destaques nossos).

Seria o poeta um aprendiz da modernidade, no exato momento em que abandona a métrica e a técnica características dos poetas parnasianos e simbolistas? As palavras de Monteiro não encontram eco nas palavras de Octávio de Faria que explica que, em $\mathbf{O}$ ritmo dissoluto: “É o momento em que o poeta, vencendo as últimas barreiras da sujeição a regras que o tolhem demais, atinge a sua forma mais agradável". (BANDEIRA, 1984, p. 75).

Mas, com a perspicácia inconfundível de quem trabalha o verso na valorização do instante, Bandeira afirma que seu terceiro livro é seu momento de transição para a afinação poética à qual ele chegou, em várias instâncias, desde o verso livre, até os versos rimados, desde a expressão de suas ideias e sentimentos à completa e almejada liberdade que lhe permitiu a amplitude de Libertinagem, seu livro seguinte.

Novamente, nosso viajante dessa vez se encontra em um trânsito que se delineia como um dos momentos mais estudados da poética do criador de "Alumbramento". Nesse momento ímpar, o antigo e o novo se cruzam, tocandose, criando a modernidade desejada, em manifestos modernos.

"E foram felizes para sempre", forma mais comum de se terminar uma história que começa com era uma vez. Mas, o que será que aconteceu com o adulto? Constituiu-se poeta, um poeta que em sua obra provoca, mescla o prosaico e o poético, debruça-se sobre a realidade brasileira, pelo olhar dos humildes e de seu cotidiano, apresentando questões gerais de estética, de forma bem humorada e aparentemente despretensiosa.

E a criança, aquela que o poeta foi incessantemente buscar na infância? Cremos, e que nos desculpem os críticos e teóricos que não concordarem, que se encontra camuflada na denominação que o poeta se deu: menor. Obviamente, não simplesmente uma questão de tamanho, de importância, mas menor, porque o poeta sabe que "poetar" é algo que se constrói aos poucos, no dia a dia, de desencanto em desencanto, vislumbrando uma paisagem noturna que, a partir de "Cartas de meu avô", alcança a plenitude, que pode ser obtida ao som d"Os sapos", quem sabe de Debussy, ou simplesmente, contemplar o silêncio dos balõezinhos, definindo-se em um auto soneto: 
Poeta chamam ao ser por mim cumprido.

Levo mundo em meus pés ultravagantes.

Um pássaro nas veias. E ao ouvido

Um anjo de conselhos inquietantes.

Se quixotesco, ao que é meu apelido

- Cuadra - e enviai: questor de rocinantes, Assim terá o pretexto cavalgantes

Meu interior ginete enlouquecido.

Sou o que fui. Como home, verdadeiro.

Sonhador, como poeta, e estreleiro.

Como cristão, de espinhos coroado.

E pois que a morte ao cabo a tudo vence,

Pablo Antônio, à tua cruz entrelaçado

Suba em flor teu cantar nicaraguense.

(BANDEIRA, 2007, p. 432).

O sujeito lírico se classifica como poeta que vaga por tempos e espaços indefiníveis, como um arauto carrega vidas por onde passa e por elas se expressa. Constitui-se como um homem que só se completa a partir do menino que foi. Um ser que sonha e consegue com as palavras exatas, exaltadas, romper os limites da fronteira que separa seu interior de seu exterior.

O menino como pai do homem, que sonha, que vira voz e que transforma em seus os sentimentos do mundo. E, diante da "indesejada das gentes", apresentase humano, como tantos outros homens que ele representa e com quem dialoga. Um grande poeta menor/menos, viajante que assim se definiu, antes de se reunir a todos que, de uma forma ou de outra, estão adormecidos:

- Estão todos dormindo

Estão todos deitados

Dormindo

Profundamente.

(BANDEIRA, 2007, p.139-140).

E, mais uma vez, as palavras viajam e dialogam com outras tão próximas e a um só tempo tão distantes, capazes de encerrar momentos de memória que compõem esse menino/homem/poeta que soube semear em pleno deserto, entre outros semeadores de palavras. E, de um modo ou de outro, nos permite perceber, através das palavras encontradas entre papéis de uma das personagens de $\mathbf{O}$ outro pé da sereia (2006), como sua obra e vida valeram a pena: 


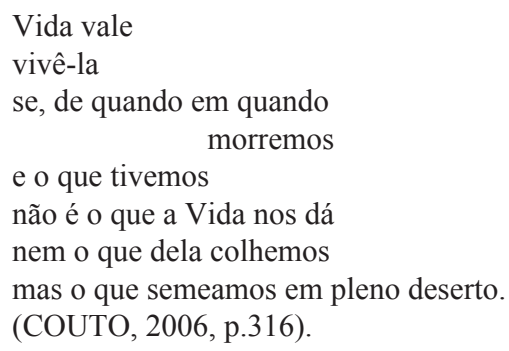

Bandeira, como poucos, soube viver e dar vida às palavras, pois encontrou a morte em alguns momentos, buscando e recebendo o que lhe foi ofertado, colheu, plantou, preparou a mesa e a divide até hoje com seus comensais, semeando simplicidade, cotidiano e poesia em muitos desertos pelos quais sua obra peregrina.

\begin{abstract}
This text pretends to analyze how travels overtake time and space, tradition and modernity in Manuel Bandeira's poetry by recovering, in a simple way, the representations of the social imaginary, the imagistic relationships operating in the affective-social memory of a culture. Still, the text intends to demonstrate that Bandeira's poetry helps maintain the contact with routine and collective memory which operate as repositories of reminiscences recollected along with life experiences. Supported by Bronislaw Baczko`s reflections on Bandeira's work, the article intends to give evidence that such elements incorporate distinct worldviews, mode behaviors and life styles, registering movements for the preservation of the status quo but also announcing changes.
\end{abstract}

Keywords: Manuel Bandeira. Travel. Memory. Tradition and modernity. Social imaginary.

Referências

ARRIGUCCI JR, David. A beleza humilde e áspera. In: BANDEIRA, Manuel. Libertinagem - Estrela da manhã. Edição Crítica. Coordenação de Giulia Lanciani. São Paulo: ALLCA; Scipione, 1998, p. 185-235.

BANDEIRA, Manuel. Itinerário de pasárgada. 3 ed. Rio de Janeiro: Nova 
Fronteira,1984.

BANDEIRA, Manuel. Estrela da vida inteira. Rio de Janeiro: Nova Fronteira, 2007.

BANDEIRA, Manuel. In: República das Letras. Rio de Janeiro: Gráfica Olímpica, 1968, p.58. Entrevista concedida a Homero Senna.

BACHELARD, Gaston. O direito de sonhar. 4 ed. Rio de Janeiro: Bertrand Brasil.1994.

BACHELARD, Gaston. A poética do devaneio. São Paulo: Martins Fontes, 1988. 205p.

BACHELARD, Gaston. A poética do espaço. São Paulo; Martins Fontes, 1989. $242 \mathrm{p}$.

BACHELARD, Gaston. A terra e os devaneios do repouso: ensaio sobre as imagens da intimidade. São Paulo: Martins Fontes, 1990, 256p.

CAMPOS, Haroldo de. Bandeira o deconstelizador. In: BANDEIRA, Manuel. Libertinagem - Estrela da manhã. Edição Crítica. Coordenação de Giulia Lanciani. São Paulo: ALLCA; Scipione, 1998, p. 653-658.

DURAND, Gilbert. A imaginação simbólica, São Paulo: Cultrix, EDUSP, 1988. $114 \mathrm{p}$.

HALBWACHS, Maurice. A memória coletiva. São Paulo: Vértice, 1990.

MOURA, Murilo Marcondes de Moura. Manuel Bandeira. São Paulo: Publifolha, 2001.

NORA, Pierre. Entre Memória e História: a problemática dos lugares. In: Projeto História. São Paulo: PUC, n. 10, pp. 07-28, dezembro de 1993.

POLLAK, Michael. Memória, esquecimento, silêncio. In: Estudos históricos. Rio de Janeiro, vol.2, nº 3, 1989.

ROSEBAUM, Yudith. A infância revisitada. In: Manuel Bandeira: uma poesia da ausência. 2ed. São Paulo: Edusp, 2002.

ROUSSO, Henry. A memória não é mais o que era. IN: FERREIRA, Marieta de Moraes \& AMADO, Janaína. Usos e abusos da história oral. RJ: FGV, 2002, p. 95 .

SENNA, Jorge de. Da poesia maior e menor a propósito de Manuel Bandeira. In: BANDEIRA, Manuel. Libertinagem - Estrela da manhã. Edição Crítica. Coordenação de Giulia Lanciani. São Paulo: ALLCA; Scipione, 1998, p. 635-642. 
SILVA, Maximiniano de Carvalho. Manuel Bandeira: lembranças e impressões. In: Homenagem a Manuel Bandeira, 1986-1988. Niterói: UFF/Presença, 1989. 